Journal of Patient-Centered

\title{
Role of Echocardiography in the Intensive Care Unit: Overview of the Most Common Clinical Scenarios
}

\author{
Luca Longobardo \\ Concetta Zito \\ Scipione Carerj \\ Giuseppe Caracciolo \\ Bijoy K. Khandheria
}

Follow this and additional works at: https://aah.org/jpcrr

Part of the Analytical, Diagnostic and Therapeutic Techniques and Equipment Commons, Cardiology Commons, Cardiovascular Diseases Commons, and the Critical Care Commons

\section{Recommended Citation}

Longobardo L, Zito C, Carerj S, Caracciolo G, Khandheria BK. Role of echocardiography in the intensive care unit: overview of the most common clinical scenarios. J Patient Cent Res Rev. 2018;5:239-43. doi: $10.17294 / 2330-0698.1631$

Published quarterly by Midwest-based health system Advocate Aurora Health and indexed in PubMed Central, the Journal of Patient-Centered Research and Reviews (JPCRR) is an open access, peer-reviewed medical journal focused on disseminating scholarly works devoted to improving patient-centered care practices, health outcomes, and the patient experience. 


\title{
Role of Echocardiography in the Intensive Care Unit: Overview of the Most Common Clinical Scenarios
}

Luca Longobardo, MD, ${ }^{1}$ Concetta Zito, MD, PhD, ${ }^{1}$ Scipione Carerj, MD, ${ }^{1}$ Giuseppe Caracciolo, MD, PhD, ${ }^{2}$ Bijoy K. Khandheria, MD²,3

${ }^{1}$ Department of Clinical and Experimental Medicine - Section of Cardiology, G. Martino General Hospital, University of Messina, Messina, Italy; ${ }^{2}$ Aurora Cardiovascular Services, Aurora Sinai/Aurora St. Luke's Medical Centers, University of Wisconsin School of Medicine and Public Health, Milwaukee, WI; ${ }^{3}$ Marcus Family Fund for Echocardiography (ECHO) Research and Education, Milwaukee, WI

\begin{abstract}
The intensive care unit (ICU) is among the more important settings in which echocardiography plays a pivotal role. The ease of use, speed of execution, and completeness of information on heart anatomy and function that echocardiography is able to provide makes this tool the perfect diagnostic technique in patients for whom exhaustive information must be quickly obtained by physicians who sometimes lack specific skills in cardiovascular imaging. However, the clinical entities encountered by ICU clinicians are often difficult to distinguish and patient symptoms may not be obvious. This brief review describes three common clinical scenarios that benefit from echocardiography in the ICU, based on symptoms frequently claimed by patients admitted to the ICU. For each symptom we describe the most likely clinical possibilities, underlining the fundamental role that echocardiography plays in the differential diagnosis, and the echocardiographic elements most relevant to obtain the correct diagnosis and to guide treatment. (J Patient Cent Res Rev. 2018;5:239-243.)
\end{abstract}

Keywords intensive care unit; echocardiography; cardiogenic shock; cardiac tamponade; pulmonary embolism

$\mathrm{E}$ chocardiography is a first-line tool for a comprehensive evaluation of patients admitted to the intensive care unit (ICU). It is noninvasive, safe, comparatively inexpensive, widely available, and allows for an anatomical, functional, and hemodynamic assessment of the heart. Transthoracic echocardiography (TTE) is able to provide satisfactory performance in a substantial percentage of patients. ${ }^{1}$ On the other hand, when the quality of the ultrasound signal is poor, or in certain clinical settings such as acute aortic diseases and valvular diseases, transesophageal echocardiography (TEE) may provide a clearer evaluation.

Correspondence: Bijoy K. Khandheria, MD, Aurora Cardiovascular Services, Aurora St. Luke's Medical Center, 2801 W. Kinnickinnic River Parkway, \#840, Milwaukee, WI 53215 (publishing22@aurora.org)
As suggested in the latest recommendations by Levitov et al, ${ }^{2}$ echocardiography is able to provide diagnostic information for several clinical scenarios (Table 1), which we will classify according to the most evident symptom at patient presentation to the ICU (Figure 1). In addition to the invaluable information obtained from a cardiac echo, the same probe can be used to ultrasound the lungs and augment the diagnostic scope of the echo, ${ }^{3}$ which has become an ICU standard of care and is beyond the scope of this review.

\section{Hypotension}

Hypotension is a frequent finding in unstable patients in the ICU. Persistent hypotension can evolve into shock, and so-called "cardiogenic shock" is the final stage of several cardiovascular diseases. The clinical conditions that most commonly determine hypotension include severe left ventricle (LV) systolic dysfunction and all the causes that induce LV underfilling due to 
Table 1. Common Clinical Scenarios Requiring Echocardiographic Assessment in Intensive Care Unit

Hemodynamic instability

Left and/or right ventricular failure

Acute coronary syndrome and its complications

Hypovolemia

Acute valvular dysfunction

Infective endocarditis

Cardiac tamponade

Pulmonary embolism

Aortic dissection and rupture

hypovolemia (eg, dehydration, bleeding, anaphylaxis, sepsis) or elevated LV filling pressure (eg, acute valvular disease, cardiac tamponade, significant LV remodeling).

The first step to obtain the proper diagnosis in a hypotensive patient is the evaluation of LV systolic function. LV systolic dysfunction could be due to cardiomyopathies, acute myocarditis, severe acidosis, or more commonly, acute coronary syndrome and its complications. Echocardiography allows a comprehensive evaluation of global LV systolic function through the calculation of LV ejection fraction (LVEF), stroke volume, and cardiac output, as well as wall motion abnormalities. When image quality is poor and the tracing of endocardium is difficult, contrast agents should be considered to improve endocardial delineation. ${ }^{4,5}$ LVEF and cardiac output are reduced when LV systolic function is decreased; the evidence of a normal or supernormal cardiac output with an impaired LV systolic function should direct the diagnosis to septic shock, as revealed by a markedly impaired LV systolic function, ${ }^{6}$ whereas cardiac output is preserved by a significantly low systemic vascular resistance that boosts LV unloading.

LV underfilling is detected frequently in patients with reduced volume load or in patients with LV dysfunction. In the former, LV filling pressure will be low and these patients benefit from fluid administration, whereas in the latter, LV filling pressure will be significantly increased and these patients benefit from diuretics and fluid restriction. Until a few years ago, the evaluation

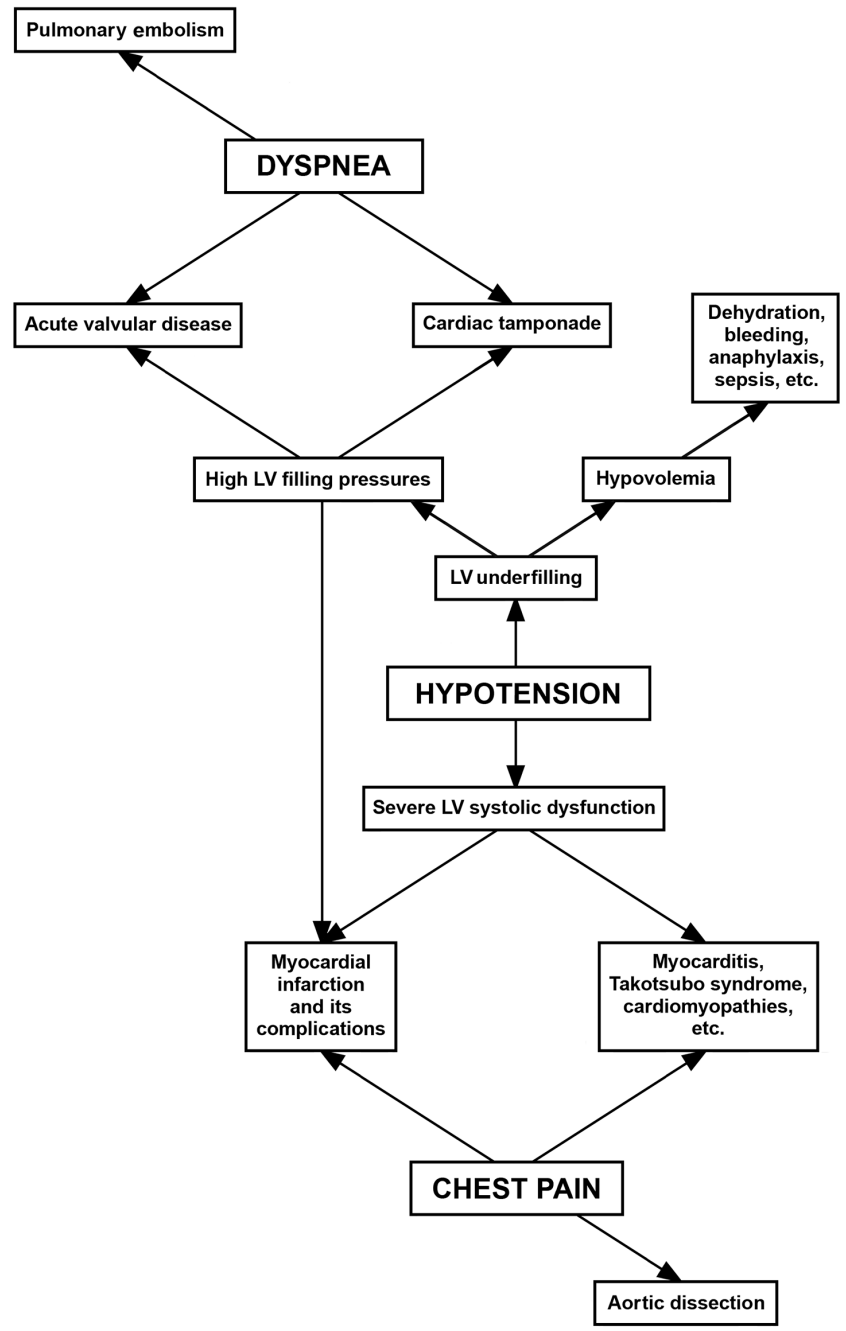

Figure 1. Classification of clinical scenarios according to their typical presenting symptoms.

of LV filling status was obtained invasively by SwanGanz catheter, but in recent years TTE has proved to be a reliable and accurate tool for the assessment of left atrial and ventricular pressures.

Acute valvular regurgitation and cardiac tamponade are two of the primary causes of hypotension and elevated LV filling pressures. Acute mitral regurgitation may be due to spontaneous chordae tendineae rupture, endocarditis, and papillary muscle rupture after acute myocardial infarction, whereas acute aortic regurgitation may be secondary to endocarditis or type A aortic dissection. TEE is the gold standard technique for an accurate assessment of valvular disease and allows the grading of the alteration as well as detection of 
the primary causes. The typical findings in acute mitral regurgitation include a severe, often eccentric, regurgitant jet, a torn chorda and/or a flail leaflet, and evidence of vegetations and leaflet perforation or disruption, ${ }^{7,8}$ which are usually associated with hyperdynamic LV, severe diastolic dysfunction, pulmonary hypertension, and various degrees of right ventricular (RV) dilatation. Similar findings can be detected in acute aortic regurgitation, in which evidence of vegetations, dilated aortic root, and aortic intimal flap suggest the correct diagnosis. ${ }^{7,8}$

Cardiac tamponade is fast accumulation of fluid in the pericardium. It can be due to myocardial perforation/ rupture secondary to catheter-based interventions or due to myocardial infarction, proximal ascending aorta dissection, pericardial metastasis, etc. The presence of pericardial effusion can be easily detected by TTE in parasternal, apical, and subcostal views (Figure 2 ), but it is fundamental to distinguish the presence of pericardial effusion, even when abundant, from tamponade, the predominant characteristic of which is hemodynamic impairment. Accordingly, common echocardiographic findings supporting a diagnosis of tamponade include swinging of the heart, early diastolic collapse of the right ventricle, late diastolic collapse of the right atrium, abnormal ventricular septal motion, respiratory variability greater than $25 \%$ in mitral inflow velocity, respiratory variation in ventricular chamber size, and inferior vena cava (IVC)

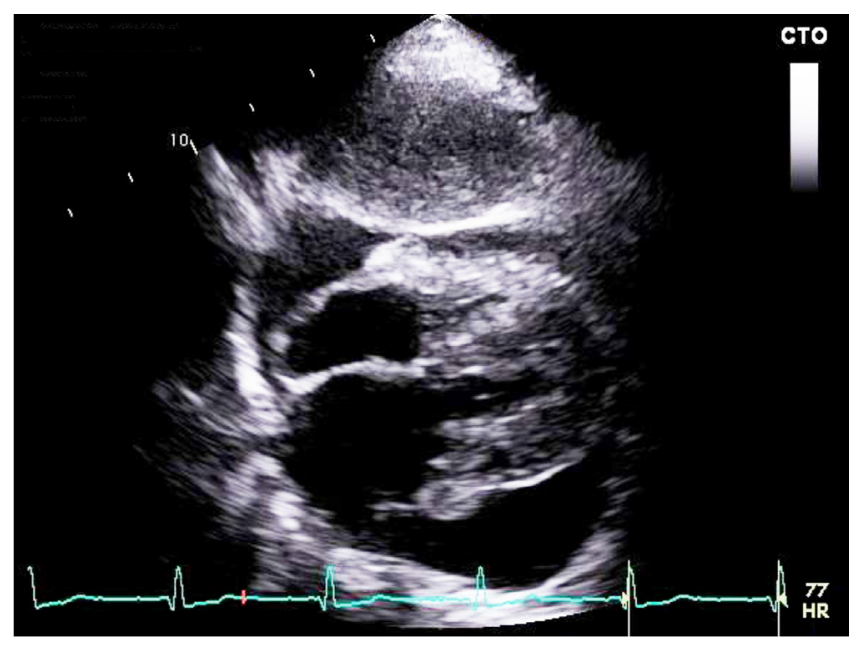

Figure 2. Echocardiogram in subcostal view that shows a significant pericardial effusion all around the heart. plethora. ${ }^{9}$ Finally, TTE plays a key role in guiding pericardiocentesis, providing information about needle orientation and position within the pericardium.

\section{Dyspnea}

Dyspnea is commonly associated with hypotension in several of the clinical scenarios already discussed, but it is the most evident symptom in acute pulmonary embolism. TTE can provide only indirect clues of pulmonary embolism, whereas TEE should improve the diagnosis, as it is able to detect thrombi in pulmonary arteries with high accuracy. ${ }^{10}$ Massive or submassive pulmonary embolism causes a sudden increase in RV afterload which, in turn, causes dilatation of pulmonary arteries, RV enlargement, and systolic dysfunction, typically involving the basal and medium segments and sparing the apex (McConnell's sign). ${ }^{11}$ Consequently, the right atrium becomes dilated, tricuspid regurgitation is significant, systolic pulmonary artery pressure (sPAP) is increased, flattening of the interventricular septum is detectable, and IVC is dilated with reduced respiratory variations. ${ }^{12}$

IVC diameter is a useful mirror of the right atrial pressure (RAP) - considered normal when IVC has normal diameter $(12-20 \mathrm{~mm})$ and variations of greater than $50 \%$ with breath but considered severely increased when IVC is dilated and respiratory changes are reduced ${ }^{13}$ (Table 2). In mechanically ventilated patients, the IVC diameter is less accurate in estimating RAP, thus, superior vena cava diameter and respiratory changes should be evaluated by TEE for diagnosis of pulmonary embolism. ${ }^{14}$ sPAP can be estimated by adding the systolic pressure gradient between the pulmonary artery and the right ventricle, quantified by continuous Doppler of tricuspid regurgitation, ${ }^{15}$ to the RAP, along with estimation of diastolic and mean pulmonary artery pressures by assessment of pulmonary regurgitation. A comprehensive evaluation of all these parameters provides an accurate assessment of the hemodynamic state of the right ventricle and can suggest the diagnosis of pulmonary embolism.

Acute heart failure and myocardial infarction are other common leading causes of dyspnea in patients admitted to the ICU. In these cases, TTE is a very useful tool for performing diagnosis, estimating LV systolic and diastolic function, and guiding patient management. ${ }^{16}$ 
Table 2. Estimated Values of Right Atrial Pressure According to IVC Diameter and Respiratory Changes*

\begin{tabular}{ccc}
\hline IVC diameter & IVC respiratory changes & Estimated right atrial pressure \\
\hline$<21 \mathrm{~mm}$ & $>50 \%$ & $3 \mathrm{mmHg}($ range: $0-5 \mathrm{mmHg})$ \\
$<21 \mathrm{~mm}$ & $<50 \%$ & $8 \mathrm{mmHg}($ range: $5-10 \mathrm{mmHg})$ \\
$>21 \mathrm{~mm}$ & $>50 \%$ & $8 \mathrm{mmHg}($ range: $5-10 \mathrm{mmHg})$ \\
$>21 \mathrm{~mm}$ & $<50 \%$ & $15 \mathrm{mmHg}($ range: $10-20 \mathrm{mmHg})$ \\
\hline
\end{tabular}

${ }^{*}$ Per 2015 guidelines by the European Society of Cardiology and European Respiratory Society for diagnosis and treatment of pulmonary hypertension. ${ }^{13}$

IVC, inferior vena cava.

\section{Chest pain}

Chest pain is usually the first symptom of acute coronary syndrome and its complications and can be found in several clinical settings associated with LV systolic dysfunction (previously discussed). However, another important potential cause of chest pain that should always be considered in the ICU is aortic dissection. TTE allows a good evaluation of the aortic root, ascending aorta, and proximal portion of aortic arch, but it is not able to assess the distal portion of arch and descending thoracic aorta; thus, TTE cannot accurately exclude type B aortic dissection. The diagnosis can be improved by TEE, which allows a better visualization of the descending aorta. ${ }^{17}$ However, sometimes assessment of the distal ascending aorta and proximal arch is difficult, so computed tomography must be performed. Necessary elements for the diagnosis of aortic dissection are evidence of the true and false lumen separated by the intimal flap.

\section{Summary}

Echocardiography is a fundamental tool for the management of patients in the intensive care unit because it allows a comprehensive evaluation of cardiac anatomy, function, and hemodynamics, providing vital information for the diagnosis and treatment of the pathological conditions most commonly faced in ICU patients.

\section{Acknowledgments}

The authors gratefully acknowledge the editorial assistance of Susan Nord and Jennifer Pfaff of Aurora Cardiovascular Services and the figure preparation of Brian Miller and Brian Schurrer of Aurora Research Institute (Milwaukee, WI).

\section{Author Contributions}

Study conception: Longobardo, Zito, Carerj, Khandheria. Data acquisition or analysis: Longobardo, Zito, Caracciolo. Manuscript drafting: Longobardo, Zito. Critical revision: Caracciolo, Carerj, Khandheria

\section{Conflicts of Interest}

None.

\section{Patient-Friendly Recap}

- Echocardiography, a noninvasive heart imaging system, is a fundamental tool for the management of patients admitted to the intensive care unit.

- Echocardiography allows a comprehensive evaluation of cardiac anatomy, function, and hemodynamics.

-When viewed in the context of a patient's presenting symptoms, this vital information can be used by clinicians to determine appropriate diagnoses or guide treatment.

\section{References}

1. Joseph MX, Disney PJ, Da Costa R, Hutchison SJ. Transthoracic echocardiography to identify or exclude cardiac cause of shock. Chest. 2004;126:1592-7. CrossRef

2. Levitov A, Frankel HL, Blaivas M, et al. Guidelines for the appropriate use of bedside general and cardiac ultrasonography in the evaluation of critically ill patients-part II: cardiac ultrasonography. Crit Care Med. 2016;44:1206-27. CrossRef

3. Gargani L. Lung ultrasound: a new tool for the cardiologist. Cardiovasc Ultrasound. 2011;9:6. CrossRef

4. Mulvagh SL, Rakowski H, Vannan MA, et al. American Society of Echocardiography Consensus Statement on the Clinical Applications of Ultrasonic Contrast Agents in Echocardiography. J Am Soc Echocardiogr. 2008;21:1179-201. CrossRef 
5. Treiber SC, Khandheria BK. The value of contrast echocardiography. J Patient Cent Res Rev. 2016;3:40-7. CrossRef

6. Parker MM, Shelhamer JH, Bacharach SL, et al. Profound but reversible myocardial depression in patients with septic shock. Ann Intern Med. 1984;100:483-90. CrossRef

7. Colreavy FB, Donovan K, Lee KY, Weekes J. Transesophageal echocardiography in critically ill patients. Crit Care Med. 2002;30:989-96. CrossRef

8. Oh JK, Seward JB, Khandheria BK, et al. Transesophageal echocardiography in critically ill patients. Am J Cardiol. 1990;66:1492-5. CrossRef

9. Adler Y, Charron P, Imazio M, et al. 2015 ESC Guidelines for the diagnosis and management of pericardial diseases: the Task Force for the Diagnosis and Management of Pericardial Diseases of the European Society of Cardiology (ESC). Eur Heart J. 2015;36:2921-64. CrossRef

10. Torbicki A, Pruszynski B, Chlebus M, et al. Noninvasive diagnosis of suspected severe pulmonary embolism: transesophageal echocardiography vs spiral CT. Chest. 1997;112:722-8. CrossRef

11. McConnell MV, Solomon SD, Rayan ME, Come PC, Goldhaber SZ, Lee RT. Regional right ventricular dysfunction detected by echocardiography in acute pulmonary embolism. Am J Cardiol. 1996;78:469-73. CrossRef

12. Konstantinides SV, Torbicki A, Agnelli G, et al. 2014 ESC guidelines on the diagnosis and management of acute pulmonary embolism. Eur Heart J. 2014;35:3033-69, 3069a-3069k. CrossRef
13. Galiè N, Humbert M, Vachiery JL, et al. 2015 ESC/ERS Guidelines for the diagnosis and treatment of pulmonary hypertension: the Joint Task Force for the Diagnosis and Treatment of Pulmonary Hypertension of the European Society of Cardiology (ESC) and the European Respiratory Society (ERS). Eur Heart J. 2016;37:67-119. CrossRef

14. Jue J, Chung W, Schiller NB. Does inferior vena cava size predict right atrial pressures in patients receiving mechanical ventilation? J Am Soc Echocardiogr. 1992;5:613-9. CrossRef

15. Currie PJ, Seward JB, Chan KL, et al. Continuous wave Doppler determination of right ventricular pressure: a simultaneous Doppler-catheterization study in 127 patients. J Am Coll Cardiol. 1985;6:750-6. CrossRef

16. Lancellotti P, Price S, Edvardsen T, et al. The use of echocardiography in acute cardiovascular care: recommendations of the European Association of Cardiovascular Imaging and the Acute Cardiovascular Care Association. Eur Heart JCardiovasc Imaging. 2015;16:119-46. CrossRef

17. Nienaber CA, von Kodolitsch Y, Nicolas V, et al. The diagnosis of thoracic aortic dissection by noninvasive imaging procedures. N Engl J Med. 1993;328:1-9. CrossRef

(C) 2018 Aurora Health Care, Inc. 